\title{
The Effect of a Strength Training Programme in Adolescents in Physical Education Classes El efecto de un programa de entrenamiento de fuerza en adolescentes en clases de educación física

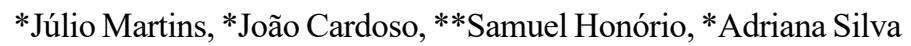 \\ *University of Beira Interior (Portugal), **Polytechnic Institute of Castelo Branco, SHERU (Portugal)
}

\begin{abstract}
Introduction: The motivation in Physical Education classes declines as students continue their studies, so its important programs that motivate and arouse interest in learning these themes, adding several and different approaches in these classes. Objective: The objective of the present study was to verify if the application of a strength circuit in high-school students could cause improvements in the strength of the upper and lower limbs. Methods: We evaluated 44 students $(\mathrm{M}=24$ / $\mathrm{F}=20$ ) of the 12th year in high school (EG $=22$ students and $\mathrm{CG}=22$ students). Results: Significant differences in the post-test were observed in the horizontal jump, with a higher mean in the experimental group compared to the control group. In the $1 \mathrm{~kg}$ medical ball throwing the differences were significant in both moments (pre and post-test), when comparing the groups, with a superior mean in the experimental group. In the $3 \mathrm{~kg}$ medicinal ball throwing, significant differences were also observed in both moments, comparing the performance of both groups. The push-up tests did not present significant differences in the pre-test, but showed significant differences in the post-test, with higher means in the experimental group. Conclusions: Through the applied training program, with a duration of 15 minutes, it was possible to verify that the experimental group obtained higher gains, when compared to the control group, for all the variables under study.
\end{abstract}

Keywords: Learning, Strength Training, Body development, Muscle Mass, Physical Education.

Resumen. Introducción: la motivación en las clases de Educación Física disminuye a medida que los estudiantes continúan sus estudios, por lo que sus importantes programas motivan y despiertan interés en aprender estos temas, agregando vários Y diferentes enfoques en estas clases. Objetivo: El objetivo del presente estudio fue verificar si la aplicación de un circuito de fuerza en estudiantes de escuela secundaria podría causar mejoras en la fuerza de las extremidades superiores e inferiores. Métodos: Evaluamos 44 estudiantes ( $M=24$ $/ F=20)$ del $12^{\circ}$ año en la escuela secundaria $(E G=22$ estudiantes y $C G=22$ estudiantes). Resultados: Se observaron diferencias significativas en la prueba posterior en el salto horizontal, $\operatorname{con} p<0.05$, con una media más alta en el grupo experimental en comparación con el grupo control. En el lanzamiento de balón médico de $1 \mathrm{~kg}$, las diferencias fueron significativas en ambos momentos (antes y después de la prueba), al comparar los grupos, con una media superior en el grupo experimental. En el lanzamiento de balón medicinal de $3 \mathrm{~kg}$, también se observaron diferencias significativas en ambos momentos, comparando el rendimiento de ambos grupos. Las pruebas de flexión no presentaron diferencias significativas en la prueba previa, pero mostraron diferencias significativas en la prueba posterior, con medias más altas en el grupo experimental. Conclusiones: A través del programa de entrenamiento aplicado, con una duración de 15 minutos, fue posible verificar que el grupo experimental obtuvo mayores ganancias, en comparación con el grupo de control, para todas las variables en estudio.

Palabras clave: aprendizaje, entrenamiento de fuerza, desarrollo corporal, masa muscular, educación física.

\section{Introduction}

Motivation for Physical Education classes declines as students continue their studies, so it is important to develop PE programs that motivate and arouse interest in learning thematic issues (Mowling, Brock, Eiler \& Rudisill, 2004). In addition, it was concluded that these programs within the PE discipline are a determinant factor for establishing physical activity behaviour's during adolescence and adulthood (Shephard \& Trudeau, 2000; Álvarez, López, Gómez, Brito \& González, 2017), because this application directly influences adolescents, providing in a positive path in their daily participation (Morgan, Beighle \& Pangrazi, 2007). However, taking in consideration the low global levels of daily PA(Pate, Ward, Saunders, Felton, Dishman \& Dowda, 2005), it is expected that these programs will not be as tight as they intended to be, making the motivation of adolescents unfeasible(Wallhead, Garn \& Vidoni, 2014).

Luke and Sinclair (1992) concluded that curricular content is a determining factor for the development of students' opinions regarding PE classes. More specifically, through a study carried out, it was concluded that the performance of physical fitness activities generates a negative attitude by Fecha recepción: 22-04-19. Fecha de aceptación: 20-11-19
Samuel Honório

samuelhonorio@hotmail.com the students (Tannehill \& Zakrajsek, 1994), showing a decrease in the last decades among children and adolescents ( Matton et al., 2007). However, their improvement is an extremely important factor for the integral development of the child (Malina, 2001), also playing a central role in the health of the individual during adulthood (Matton, Thomis, Wijndaele, Duvigneaud, Beunen, Claessens \& Lefevre, 2006). There is evidence that physical inactivity and consequently lack of physical fitness increase the risk of morbidity and mortality, and that their training assists with or slows the development of certain coronary diseases, stroke, hypertension, some types of cancer, especially in adulthood (Matton et al., 2006).

In addition, there is evidence that depression and anxiety may improve with the training of physical fitness components, and it is also relevant to mention the relevance of these factors to the health of muscles, bones and joints (Bouchard, Shephard \& Stephens, 1994). Given this evidence, school plays a major role in promoting increased levels of physical activity and consequently physical fitness (Strong, Malina, Blimkie, Daniels, Dishman, Gutin \& Pivarnik, 2005; Medrano \& Mateos, 2018), mainly through the development of training programs (Marques, Zajac, Pereira \& Costa, 2011; Rodríguez-Rodríguez, Rosa \& Flores, 2017). This is because, many of the children and adolescents only practice vigorous physical activity in schools, specifically during Physical Education classes (Coleman, Heath \& Alcalá, 2004), 
performing this discipline as an essential function for the development of physical fitness related to health and the maintenance of a healthy lifestyle (Marta, Marinho, Izquierdo \& Marques, 2014).

According to these ideas and based on all that has been mentioned previously, more and more physical fitness components are considered by PE teachers, since levels of obesity have also increased time (Morrow, Fulton, Brener \& Kohl, 2008; Guillamón, Canto \& López, 2019). It is considered that children and adolescents are normally instructed to participate in activities of aerobic nature, such as athletics or swimming, however scientific studies emphasize the importance and beneficial aspects of strength training, which is prepared in a conditioned and adjusted to the characteristics is very safe and effective (Faigenbaum \& Mediate, 2006). Strength training can be defined as a conditioning method, which encompasses the gradual appeal to resistive loads and a myriad of training styles, such as: free weights, weight machines, elastics, medical balls, body weight, to improve health, physical fitness and sports performance (Santos, Marinho, Costa, Izquierdo \& Marques, 2011).

In addition to providing improvements in motor skills, increased muscle strength and endurance performance, frequent participation in a strength training program in youth triggers relevant health (Faigenbaum \& Myer, 2010a; Davis, 2003), improving body composition and motor coordination (Faigenbaum \& Myer, 2010a). According to Stricker (2002) strength training also provides an improvement in blood lipid profiles and mental health. In addition, muscle strength also has a positive association with school performance (Coe, Pivarnik, Womack, Reeves \& Malina, 2012; Candia-Luján, Escudero, Cruz, Fierro, Carrasco-Legleu \& Candia-Sosa, 2018).

Based on all the benefits of strength training mentioned above, there are currently several health-related recommendations that aim to increase the number of youths involved in muscle-strengthening activities, with schools and sports centres betting on each (Myer et al., 2011). Also, it is important to note that in the present study, this is because a stronger and more powerful musculoskeletal system makes it possible for children and adolescents to perform body movements more efficiently, decreasing their pre - disposition to contracting sports injuries (Faigenbaum \& Myer, 2010b; Krsmanoviæ, Mikalaèki, Nebojša, Simiæ \& Ruiz-Montero, 2018). For all these reasons, muscle strength should be a priority in any sports development program (Lloyd \& Oliver, 2012) and should be performed at least 3 times a week (Organization, 2010; Enriquez-Reyna, Bautista \& Orocio, 2019).

More specifically, and according to the existing literature, the effect of strength training can be influenced by several factors, such as age, maturation, gender, frequency, duration and intensity of the training applied (Falk \& Tenenbaum, 1996). Therefore, it is argued that children present a gradual increase in strength and muscular power from 3 years of age until puberty for boys and up to 15 years for girls (Beunen \& Thomis, 2000). In the same sequence of ideas, it was concluded that children present greater adaptations at the motor level (Behringer, Heede, Matthews \& Mester, 2011), and this is an important time for them to develop their strength and power that can progressively be increased through training strategies (Faigenbaum, Lloyd, MacDonald \& Myer, 2016; Jimenez, Pardo, Quintero \& Muñoz, 2019). It is also important to mention that children present a lower risk of contracting injuries and muscle strains derived from strength training when compared with adults (Myer, Quatman, Khoury, Wall \& Hewett, 2009). Given this situation, it was decided to implement a training program of 8 weeks at the level of the strength component (upper and lower limbs), which had already obtained beneficial results in young adolescents (Marques et al., 2011; Marta et al., 2013; Marta et al., 2014) in order to find out if a given circuit provided increments at the level of muscle strength.

The objective of the present study was to verify if the application of a strength circuit in high-school students to analyse if it would cause improvements in the strength of the upper and lower limbs.

\section{Materials and Methods}

\section{Participants}

It was decided to carry out one of the tests of the Fit School program, as well as 2 specific tests, which were applied at the beginning and at the end of the present study. The present study was applied to two distinct classes of the $12^{\text {th }}$ grade in high school, with a total of 44 students ( 24 male and 20 female), with one as the experimental group ( 22 students), while the other as the control group (22 students). the control group did not perform the strength circuit, only the tests to gauge the effects caused only by the Physical Education classes. Through the analysis of the following tables it is also possible to observe that in the experimental group the percentage of boys is significantly higher, $73 \%$ of males and $27 \%$ of females, in contrast with the control group where the percentage of girls stands out, $36 \%$ of males and $64 \%$ of females. It is important to mention that mean age for both control and experimental groups was 17.6 , where ó $=0.497$.

\section{Procedures}

Initially it will be essential to mention that prior to the application of the study in the following approach, authorization was requested from the school and from the student's parents. In the present study, a training program was implemented for 8 weeks, in order to verify if, through a strength circuit, the participants acquire improvements in the strength of the upper and lower limbs, using a longitudinal structure of repeated measurements. For this training program the sample choice was randomized (without inclusion or exclusion criteria), belonging to two groups, one being part of the control group and the other of the experimental group. It is important to note that the variables used for the study were: the horizontal jump, throwing medical balls of $1 \mathrm{~kg}$ and $3 \mathrm{~kg}$ and the push-ups. In order to evaluate the applied circuit, four tests were applied, before the circuit starts and at the end of the circuit, which will be explained next.

\section{Horizontal Jump}

The horizontal jump test aims to evaluate the explosive strength of lower limbs. Students should position themselves 
standing with their feet shoulder-width apart, next to the measuring tape, which is perpendicular. It should be noted that a tape was placed on the floor in order to mark the beginning of the jump. Thus, the student makes a leap with his feet slightly apart, in order to reach maximum distance in length (Alves, Marta, Neiva, Izquierdo \& Marques, 2016). According to the same author this distance is measured from the tape to the student's heels. It is important to mention that each of the students made 3 jumps, taking advantage of the higher value obtained for analysis. The control of the test was carried out by 3 evaluators, in order to obtain a degree of agreement of the maximum values obtained, using the average value obtained by them. It should be noted that the difference between the observations never exceeded $3 \mathrm{~cm}$.

\section{Throwing the medicinal balls of $1 \mathrm{~kg}$ and $3 \mathrm{~kg}$}

Both releases were made following the same assumptions. The student positioned perpendicularly to a tape measure, with the feet parallel, placing them next to a marked line in the floor. At the throwing moment the student held the ball with both hands above the head, with the elbows at the level of the ball, accompanied by a slight flexion of the lower limbs (Van den Tillaar \& Marques, 2013). It is important to mention that each of the students made 3 entries, and the highest value obtained was analysed. It should also be noted that the control of the test was carried out by 3 evaluators, in order to obtain a degree of agreement of the maximum values obtained, and for that reason the average value obtained by them was used. It is relevant to mention that the difference between the observations never exceeded $5 \mathrm{~cm}$.

\section{Arms Push-ups}

This is characterized by the number of flexions of the upper limbs, based on the cadence presented by the CD, presenting this as an objective to evaluate the resistance strength of the upper limbs. According to Castro-Piñero et al. (2010) the student should initially assume a plank position, elbows in extension and feet slightly apart, using the tips of the feet to maintain balance. According to the same author, the bending motion begins when the student flexes the elbows slowly, until the angle between the arm and the forearm is 90 degrees. It should be noted that the control of this test was also made using the analysis of the three evaluators. Thus, the students in the experimental group were divided into groups of 5 , each evaluator recording the number of repetitions performed, as the students stopped (of their own accord) or for an incorrect execution of the intended (essential intervention of the evaluators). At the end, and considering the values recorded, the 3 evaluators checked if they agreed with each other, not being verified changes in that level.

\section{Applied training programme}

The training program was implemented for 8 consecutive weeks and was constructed based on previous studies (Costa et al., 2016), also applied to individuals like these ones. It is important to mention that the training sessions were held twice a week, being the same distances of more than 48 hours, a relevant factor to provide the total recovery of the participating students. This training program was conducted during Physical Education classes, with a duration of 15 to
20 minutes. The adopted program had as function to promote a stimulation of the strength of the upper and lower limbs, using exercises of throwing the medicinal balls of $1 \mathrm{~kg}$ and $3 \mathrm{~kg}$ (Alves, Marta, Neiva, Izquierdo \& Marques, 2016; Costa et al. 2016). More specifically, each of the participating students was asked to perform each repetition, using their maximum velocity of the concentric phase of the movement, in order to provide the adaptation to strength training (González-Badillo \& Sánchez-Medina, 2010). In addition, it should be noted that for the sequencing and load progression an adaptation of previous scientific evidences was made (Alves, Marta, Neiva, Izquierdo \& Marques, 2016; Costa et al., 2016), which can be found in the table 1 . Before the implementation of the training program, an initial evaluation was carried out, in the week preceding this accomplishment, and a final evaluation, carried out one week after the end of this circuit.

$$
\text { Table } 1
$$

Applied Training Program for 8 Weeks.

\begin{tabular}{ccccccccc}
\hline & \multicolumn{10}{c}{ Week } \\
\hline Exercises & $\mathbf{1}$ & $\mathbf{2}$ & $\mathbf{3}$ & $\mathbf{4}$ & $\mathbf{5}$ & $\mathbf{6}$ & $\mathbf{7}$ & $\mathbf{8}$ \\
\hline Horizontal Jump & $1 \times 5$ & $1 \times 5$ & $1 \times 5$ & $1 \times 5$ & $2 \times 5$ & $2 \times 5$ & $2 \times 5$ & $2 \times 5$ \\
1Kg Throwing & $2 \times 8$ & $2 \times 8$ & $2 \times 8$ & $2 \times 8$ & $3 \times 8$ & $3 \times 8$ & $3 \times 8$ & $3 \times 8$ \\
3Kg Throwing & $2 \times 8$ & $2 \times 8$ & $2 \times 8$ & $2 \times 8$ & $3 \times 8$ & $3 \times 8$ & $3 \times 8$ & $3 \times 8$ \\
\hline
\end{tabular}

\section{Statistical Analysis}

It is important to mention that a descriptive analysis will initially be performed in order to describe the data analysed in the study. For this, some statistical independence methods were used, the $\mathrm{T}$ test for independent samples, in order to compare the two groups under study (experimental and control). It should also be noted that whenever the assumptions for the use of this same test were not verified, the MannWhitney test was used. In order to compare the evolution of the participants of both groups under study (according to the values obtained in the pre- and post-test), we used the T-test for paired samples, when normality was verified, or the Wilcoxon test when this did not happen. Normality was tested by performing the Shapiro-Wilk test $(\mathrm{n}<30)$, whose results can be verified in table 2 . All data were analysed using statistical software SPSS, version 24. It is important to indicate that a significance of $5 \%$ was assumed.

\begin{tabular}{lccc}
$\begin{array}{l}\text { Table } 2 \\
\text { Verification of the Assumption of Normality. }\end{array}$ \\
\hline & Group & Pre (p-value $)$ & Post (p-value $)$ \\
\hline Horizontal Jump & Control & 0.692 & 0.783 \\
& Experimental & 0.704 & 0.156 \\
1 Kg Throwing & Control & 0.105 & 0.166 \\
& Experimental & 0.062 & 0.149 \\
3 Kg Throwing & Control & 0.053 & 0.059 \\
& Experimental & 0.201 & $0.042^{*}$ \\
Push-ups & Control & 0.375 & 0.246 \\
& Experimental & 0.117 & $0.002^{*}$ \\
\hline${ }^{*}$ Shapiro-Wilk Test & & &
\end{tabular}

The present table was constructed in order to verify the normality of the variables under analysis. After the analysis, it is possible to observe that, for the control group, normality is always verified (for all tests, before and after the test), since $p>0.05$. However, according to the experimental group, in the $3 \mathrm{~kg}$ medical ball throwing and, in the push-ups (posttest), normality did not occur, since $\mathrm{p}<0.05$.

\section{Results}

In the table above it is possible to verify which were the variables under analysis throughout the present study. 
Through the observation of the same it is possible to also perceive that the four variables showed improvements from the pre to the post-test, after the application of the strength circuit.

After the analysis of the previous table and with respect to the horizontal jump it is possible to notice that there were significant differences only in the post-test, since $p<0.05$, the mean of the experimental group being significantly higher than the control group. Regarding the throwing of the $1 \mathrm{~kg}$ medical ball the differences were significant in both moments (pre and post), when compared to the control group and experimental group, with a higher mean in the experimental group. For the $3 \mathrm{~kg}$ medicinal ball throwing test, the differences were also significant for both moments, comparing the performance of the control group and the experimental group. Finally, the push-ups test did not present significant differences in the pre-test, but showed significant differences in the post-test, with higher means in the experimental group.

Based on the analysis of table 4 , it is possible to verify that the improvements are significant from pre to post-test, relative to the experimental group, for all variables under study, since $\mathrm{p}<0.001$. In addition, it is also feasible to realize that since the mean of the differences for all variables is always negative, the performance value is always higher in the post-test.

In contrast to what is possible to verify in the experimental group, the control group did not present significant improvements from pre to post-test in any of the variables under study, since $\mathrm{p}>0.05$.

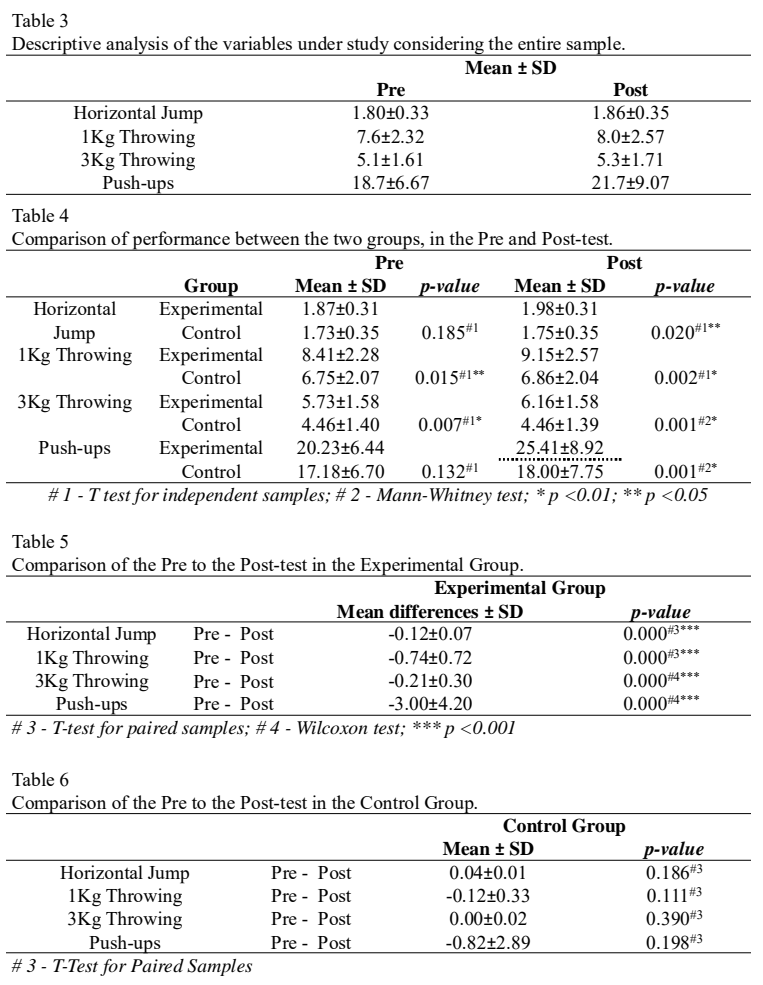

\section{Discussion}

The objective of the present study was to verify if the application of a strength circuit in $12^{\text {th }}$ students would cause improvements in the strength of the upper and lower limbs.
This training program (circuit) was designed with the intention of being applied during Physical Education classes, in a very simplified way (without great material resources), avoiding extraordinarily expenses. We have opted for a circuit training program, since this brings benefits from a pedagogical point of view and is therefore a key resource for working strength in young people (Santos et al., 2011). According to these, Dahab and McCambridge (2009) emphasizes that these youth training programs should include a variety of material, namely medicinal balls, which were used in this circuit. More specifically, based on the results obtained, it is possible to verify that there are significant differences from pre to posttest, for all variables. Therefore, the results obtained are in agreement with previous studies, which although not belonging to the same age group, developed the same exercises in the same way, achieving improvements in the strength of the upper and lower limbs (throwing of the $1 \mathrm{~kg}$ and $3 \mathrm{~kg}$ medical balls, horizontal jump) (Alves et al., 2016; Marta, Marinho, Barbosa, Izquierdo \& Marques, 2013). Given these results, it can be stated that the circuit applied to the experimental group triggered improvements in its strength (upper and lower). Comparing now the results obtained by the two distinct groups and not being the main objective of the study, it is possible to notice that there were significant differences from the pre to the post test in the launch of the $1 \mathrm{~kg}$ and $3 \mathrm{~kg}$ medical balls, and these values are also in agreement with studies already performed, but at lower ages. Santos et al. (2011) in their study obtained differences between the control group and the experimental group, for the mentioned variables, like the study under analysis.

Regarding the horizontal jump, only post-test differences were observed, probably because they were distinct classes, and therefore, it was difficult both to depart from the same level of performance. These results (significant improvements) don't agree with the results of Santos et al. (2011), for the horizontal jump variable. Regarding to the push-ups variable and although they have not been worked along the circuit, it was considered relevant to insert this component in the study, since it also works on the strength level of the upper and lower limbs. Because in all school periods the Fit School tests are performed, it was tried to realize the influence that the strength circuit could have in this component (Marques et al. 2011). Therefore, it was verified that this one showed significant improvements from the pre to the post test in the experimental group, which was not verified in the control group. However, comparing the two groups, the differences were significant only in the posttest, with little differences since they were distinct classes and because of the same factor, presenting different characteristics.

As limitations of the present study, it is important to note that the number of exercises applied is low, in the pre-test the control group already presents differences in relation to the experimental group, not considering the gains from the practice of discipline of Physical Education. In addition, there may be some oscillations due to the commitment or lack it on the part of the participants, and with respect to the measurements of the three evaluators, who, despite considering lower margins of error, may have seen some slight change in the real value. 


\section{Conclusions}

Through the applied training program, with a duration of 15 minutes, it was possible to verify that the experimental group obtained higher gains, when compared to the control group, for all the variables under study. Therefore, it seems to be important to add different and motivating programs to the Physical Education Classes in order to improve adolescent's physical skills, while the current physical classes applied do not obtain significant gains on strength adolescents. It was possible to verify that the exclusive practice of these classes (control group) did not trigger such significant gains to the level of strength in upper and lower limbs, as in the group that performed the circuit twice a week.

It is important to note that the application of this type of program does not require extraordinary material (in general, all schools have metric tapes, medical balls), nor do they lose too much of their total class time, even though in that period they are not practicing the sports required for are working on skills that can improve students' performance in the practice of these same disciplines. It is probably important to demystify, what are the assumptions inherent in the development of strength not only in children but also in young adolescents. In addition, it will also be useful to install at an early stage in students the need to work not only this valence but others, equally relevant for their integral development.

\section{Acknowledgements}

The authors would like to thanks to the school that gave permission to this study, and all individuals that participated.

This work is supported by national funding through the Portuguese Foundation for Science and Technology, I.P., under project UIDB/04045/2020 and UIDP/04045/2020.

\section{References}

Álvarez, E., López, J., Gómez, V., Brito, J. \& González, H. (2017). Influence of motivation and dispositional flow on the intention to do physical activity in adolescents from four countries, Retos, 31, 46-51.

Alves, A. R., Marta, C. C., Neiva, H. P., Izquierdo, M. \& Marques, M. C. (2016). Concurrent training in prepubescent children: the effects of 8 weeks of strength and aerobic training on explosive strength and V [Combining Dot Above] $\mathrm{O} 2 \mathrm{max}$. The Journal of Strength \& Conditioning Research, 30(7), 2019-2032.

Batez, M., Krsmanoviæ, B., Mikalaèki, M., Èokorilo, N., Simiæ, M. \& Montero, P. (2018). Morphological characteristics and motor skills of young students with different levels of engagement in physical activities. Retos, 33, 58-62.

Behringer, M., Heede, A., Matthews, M. \& Mester, J. (2011). Effects of strength training on motor performance skills in children and adolescents: a meta-analysis. Pediatric Exercise Science, 23(2), 186-206.

Beunen, G. \& Thomis, M. (2000). Muscular strength development in children and adolescents. Pediatric Exercise Science, 12(2), 174-197.

Bouchard, C., Shephard, R. \& Stephens, T. (1994). The consensus statement. Paper presented at the Physical activity, fitness, and health: International proceedings and consensus statement.

Candia-Luján, R., Escudero, B., Cruz, K., Fierro, L., CarrascoLegleu, C. \& Candia-Sosa, K. (2018). Similar bilateral asymmetry index of lower limbs muscle strength expressions in university students. Retos, 33, 34-36.

Castro-Piñero, J., Ortega, F., Artero, E., Girela-Rejón, M., Mora, J., Sjöström, M. \& Ruiz, J. R. (2010). Assessing muscular strength in youth: usefulness of standing long jump as a general index of muscular fitness. The Journal of Strength \& Conditioning Research, 24(7), 1810-1817.

Coe, D., Pivarnik, J., Womack, C., Reeves, M. \& Malina, R. (2012). Health-related fitness and academic achievement in middle school students. The Journal of sports medicine and physical fitness, 52(6), 654-660.

Coleman, K., Heath, E. \& Alcalá, I. (2004). Overweight and aerobic fitness in children in the United States/Mexico border region. Revista Panamericana de Salud Pública, 15(4), 262-271.

Costa,A., Gil, M., Sousa, A., Ensinas, V., Espada, M. \& Pereira, A. (2016). Effects of concurrent strength and endurance training sequence order on physical fitness performance in adolescent students. Journal of Physical Education and Sport, 16(4), 1202.

Dahab, K. \& McCambridge, T. (2009). Strength training in children and adolescents: raising the bar for young athletes? Sports Health, 1(3), 223-226.

Davis, R. (2003). Adolescent Strength Training in Physical Education. Strategies, 16(3), 27-28.

Enriquez-Reyna, M., Bautista, D. \& Orocio, R. (2019). Physical activity level, muscle mass and strength of community elderly women: Differences by age group. Retos, 35, 121125.

Faigenbaum, A. (2001). Strength training and children's health. Journal of Physical Education, Recreation \& Dance, 72(3), 24-30.

Faigenbaum, A., Lloyd, R., MacDonald, J. \& Myer, G. (2016). Citius, Altius, Fortius: beneficial effects of resistance training for young athletes: narrative review. Br J Sports Med, 50(1), 3-7.

Faigenbaum, A. \& Mediate, P. (2006). Effects of medicine ball training on fitness performance of high-school physical education students. Physical Educator, 63(3), 160.

Faigenbaum, A. \& Myer, G. (2010a). Pediatric resistance training: benefits, concerns, and program design considerations. Current sports medicine reports, 9(3), $161-168$.

Faigenbaum, A. \& Myer, G. (2010b). Resistance training among young athletes: safety, efficacy and injury prevention effects. British journal of sports medicine, 44(1), 56-63.

Falk, B. \& Tenenbaum, G. (1996). The effectiveness of resistance training in children. Sports Medicine, 22(3), 176-186.

Guillamón, A., Canto, E. \& López, P. (2019). Physical activity, physical fitness and self-concept in schoolchildren aged between 8 to 12 years old. Retos, 35, 236-241.

González-Badillo, J., \& Sánchez-Medina, L. (2010). Movement velocity as a measure of loading intensity in resistance 
training. International journal of sports medicine, 31(05), 347-352.

Jimenez, L., Pardo, A., Quintero, G. \& Muñoz, A. (2019). Explosive strength in older adults, training effects on maximum strength. Retos, 36, 64-68.

Lloyd, R. \& Oliver, J. (2012). The youth physical development model: A new approach to long-term athletic development. Strength \& Conditioning Journal, 34(3), 61-72.

Luke, M. \& Sinclair, G. (1992). Gender differences in adolescents' attitudes toward school physical education. Journal of Teaching in Physical Education, 11(1), 3146.

Malina, R. (2001). Physical activity and fitness: pathways from childhood to adulthood. American Journal of Human Biology, 13(2), 162-172.

Marques, M., Zajac, A., Pereira,A. \& Costa,A. (2011). Strength training and detraining in different populations: Case studies. Journal of human kinetics, 29(Special Issue), 714.

Marta, C., Marinho, D., Barbosa, T., Izquierdo, M. \& Marques, M. (2013). Effects of concurrent training on explosive strength and VO2max in prepubescent children. International journal of sports medicine, 34(10), 888896.

Marta, C., Marinho, D., Izquierdo, M. \& Marques, M. (2014). Differentiating maturational influence on training induced strength and endurance adaptations in prepubescent children. American Journal of Human Biology, 26(4), 469-475.

Matton, L., Duvigneaud, N., Wijndaele, K., Philippaerts, R., Duquet, W., Beunen, G. \& Lefevre, J. (2007). Secular trends in anthropometric characteristics, physical fitness, physical activity, and biological maturation in Flemish adolescents between 1969 and 2005. American Journal of Human Biology, 19(3), 345-357.

Matton, L., Thomis, M., Wijndaele, K., Duvigneaud, N., Beunen, G., Claessens, A. \& Lefevre, J. (2006). Tracking of physical fitness and physical activity from youth to adulthood in females. Medicine \& Science in Sports \& Exercise, 38(6), 1114-1120.

Medrano, E. \& Mateos, M. (2018). Evaluation of motivation in teenagers who practice sports in school age. Retos, 33,27-33.

Morgan, C., Beighle, A. \& Pangrazi, R. (2007). What are the contributory and compensatory relationships between physical education and physical activity in children? Research Quarterly for Exercise and sport, 78(5), 407412.0

Morrow Jr, J., Fulton, J., Brener, N. \& Kohl III, H. (2008). Prevalence and correlates of physical fitness testing in US schools - 2000. Research Quarterly for Exercise and sport, 79(2), 141-148.

Mowling, C., Brock, S., Eiler, K. \& Rudisill, M. (2004). Student motivation in physical education breaking down barriers. Journal of Physical Education, Recreation \& Dance, 75(6), 40-45.

Myer, G., Faigenbaum, A., Ford, K., Best, T., Bergeron, M. \& Hewett, T. (2011). When to initiate integrative neuromuscular training to reduce sports-related injuries in youth? Current sports medicine reports, 10(3), 155.
Myer, G, Quatman, C., Khoury, J., Wall, E. \& Hewett, T. (2009). Youth versus adult «weightlifting» injuries presenting to United States emergency rooms: accidental versus nonaccidental injury mechanisms. Journal of strength and conditioning research/National Strength \& Conditioning Association, 23(7), 20-54.

Organization, W. H. (2010). Global recommendations on physical activity for health. Geneva: World Health Organization.

Pate, R., Ward, D., Saunders, R., Felton, G., Dishman, R. \& Dowda, M. (2005). Promotion of physical activity among high-school girls: a randomized controlled trial. American journal of public health, 95(9), 1582-1587.

Rodríguez-Rodríguez, F.,Gatica, C., Rosa, F. \& Flores,A. (2017). Evaluation of physical education in secondary school, Retos, 31, 76-81.

Santos, A., Marinho, D., Costa, A., Izquierdo, M. \& Marques, M. (2011). The effects of concurrent resistance and endurance training follow a specific detraining cycle in young school girls. Journal of human kinetics, 29(Special Issue), 93-103.

Shephard, R. \& Trudeau, F. (2000). The legacy of physical education: Influences on adult lifestyle. Pediatric Exercise Science, 12(1), 34-50.

Stricker, P. (2002). Sports training issues for the pediatric athlete. Pediatric Clinics of North America, 49(4), 793802.

Strong, W., Malina, R., Blimkie, C., Daniels, S., Dishman, R., Gutin, B. \& Pivarnik, J. (2005). Evidence based physical activity for school-age youth. The Journal of pediatrics, 146(6), 732-737.

Tannehill, D. \& Zakrajsek, D. (1994). Student attitudes towards physical education: A multicultural study. Journal of Teaching in Physical Education, 13(1), 78-84.

Van den Tillaar, R. \& Marques, M. (2013). Reliability of seated and standing throwing velocity using differently weighted medicine balls. The Journal of Strength \& Conditioning Research, 27(5), 1234-1238.

Wallhead, T., Garn, A. \& Vidoni, C. (2014). Effect of a sport education program on motivation for physical education and leisure-time physical activity. Research Quarterly for Exercise and sport, 85(4), 478-487.

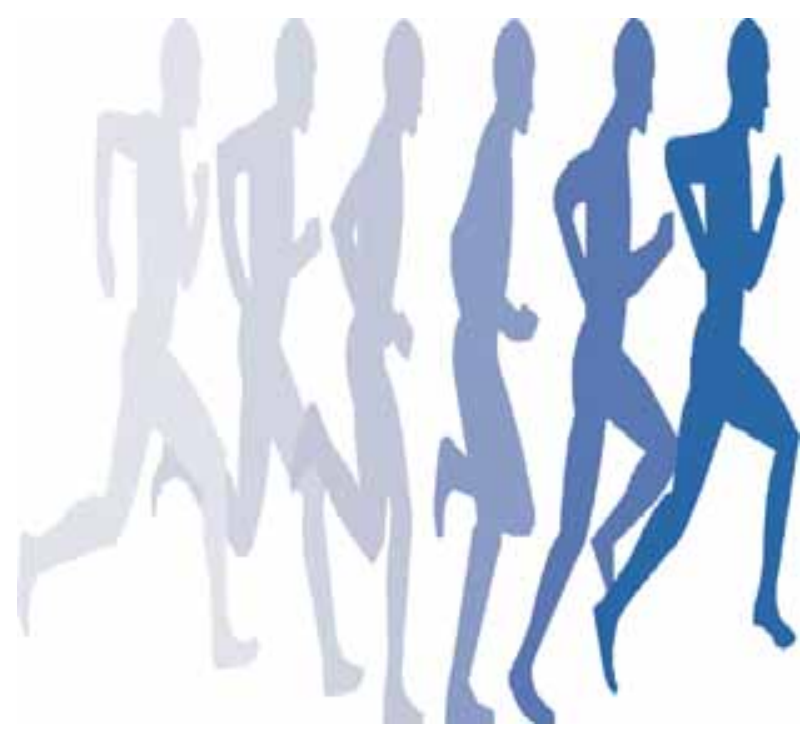

